This preprint is a first draft of a manuscript now published in a peer-reviewed journal. For all reading, downloads, and citation, please use:

Ash, Garrett I. PhD; Nally, Laura M. MD; Stults-Kolehmainen, Matthew PhD; De Los Santos, Melissa MS; Jeon, Sangchoon PhD; Brandt, Cynthia MD; Gulanski, Barbara I. MD; Spanakis, Elias K. MD; Baker, Julien S. PhD; Weinzimer, Stuart A. MD; Fucito, Lisa M. PhD. Personalized Digital Health Information to Substantiate Human-Delivered Exercise Support for Adults With Type 1 Diabetes. Clinical Journal of Sport Medicine ():10.1097/JSM.0000000000001078, January 27, 2023. | DOI: 10.1097/JSM.0000000000001078. Access at: https://oce.ovid.com/article/00042752-990000000-00091/HTML

\title{
Personalized Big Data for Type 1 Diabetes Exercise Support
}

Garrett I. Ash $\mathrm{PhD}^{1,2}$, Laura M. Nally $\mathrm{MD}^{2}$, Matthew Stults-Kolehmainen $\mathrm{PhD}^{3,4}$, Melissa De Los Santos $\mathrm{MS}^{4}$, Sangchoon Jeon $\mathrm{PhD}^{2}$, Cynthia Brandt $\mathrm{MD}^{1,2}$, Barbara I Gulanski MD ${ }^{1,2}$, Elias K. Spanakis MD ${ }^{5,6}$, Julien S. Baker $\mathrm{PhD}^{7},{ }^{*}$ Stuart A. Weinzimer $\mathrm{MD}^{2}$, *Lisa M. Fucito $\mathrm{PhD}^{2}$

${ }^{*}$ Co-senior authors

${ }^{1}$ Veterans Affairs Connecticut Healthcare System, West Haven, CT, USA

${ }^{2}$ Yale University, New Haven, CT, USA

${ }^{3}$ Yale-New Haven Hospital, New Haven, CT, USA

${ }^{4}$ Columbia University, New York, NY, USA

${ }^{5}$ Veterans Affairs Maryland Healthcare System, Baltimore, MD, USA

${ }^{6}$ University of Maryland, Baltimore, MD

${ }^{7}$ Hong Kong Baptist University, Kowloon Tong, Hong Kong

Correspondence:

Garrett I. Ash, PhD

VA Connecticut Healthcare System (11-ACSLG)

Building 35A, Rm 235

950 Campbell Avenue

West Haven, CT 06516

Phone: 203-444-3079

Fax: 203-937-3829

Email: garrett.ash@yale.edu

Co-Author Agreement: We the authors agree to the sharing of this preprint on SporR $\chi$ iv.

This work is a preprint (pre-peer review).

Please cite as: Ash GI, Nally L, Stults-Kolehmainen M, De Los Santos M, Jeon S, Brandt C, Gulanski BI, Spanakis E, Baker JS, Weinzimer SA*, Fucito LM*. (2021). Personalized big data

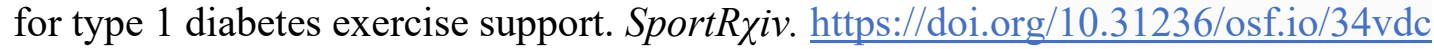
*Co-senior authors.

All authors have read and approved this version of the manuscript. This article was last modified on March 23, 2021. Author Laura Nally @drnallypants can be reached on Twitter . 


\section{Conflicts of Interest and Source of Funding}

The study was funded by the Michael and Rosemary Ryan Pediatric Diabetes Research Fund. G.I.A. is supported by a fellowship from the Office of Academic Affiliations at the United States Veterans Health Administration. E.K.S. was partially supported by the VA MERIT award (\#1I01CX001825) from the United States Department of Veterans Affairs Clinical Sciences Research and Development Service.

E.K.S. has received unrestricted research support from Dexcom (to Baltimore VA Medical Center and to University of Maryland) for the conduction of clinical trials, which (Dexcom) did not support the work monetarily or in kind. S.A.W serves as a Speaker for Medtronic and as Consultant for Zealand Pharmacetuicals; neither of these entities supported the above study. For the remaining authors none were declared.

\section{Clinical Trial Registration and Data Availability}

The trial was publicly registered on clinicaltrials.gov (NCT04204733). Individual deidentified participant data (including data dictionaries) will be shared. This includes individual participant data that underlie the results reported in any aspect of a published article (text, tables,

figures, and appendices). Other documents that will be available include the study protocol, statistical analysis plan, informed consent form, analytic code. The data will be available immediately following publication with no end date. Data will be shared with researchers who provide a methodologically sound proposal to achieve aims in the approved proposal. Proposals should be directed to Dr. Garrett Ash at Yale University (garrett.ash@yale.edu). To gain access, data requesters will need to sign a data access agreement.

\section{Acknowledgments}

The authors thank Madilyn Augustine, Jenna Burton, Irene Chernova, Anthony Cifre, Jack LaVigne, Allison McNeilly, Natalia Roberts, David Robledo, Marisa Rodgers, Chanelle 
Simmons, Kathleen Tackos, and Asiya Way for their contributions to the implementation of the study. The authors thank Dr. David Korfhagen for transcribing the interviews.

Abstract word count: 250 / 250

Manuscript word count (not counting figures, tables, references): 2,968 / 3,000 


\section{ABSTRACT}

2 Objective: Evaluate feasibility, safety, acceptability, and estimate efficacy of an exercise

3 promotion intervention for adults with type 1 diabetes (T1D) and sub-optimal baseline exercise

4 patterns.

5 Design: Single-group, 2-week baseline observation then 10-week intervention with follow-up

6 observation.

7 Setting: Community-based sample participating remotely with physician oversight

8 Participants: Volunteers 18-65 years old with T1D screened for medical readiness for exercise

9 intervention offerings. $\mathrm{N}=20$ enrolled, $\mathrm{N}=17$ completing all outcomes with $88 \%-91 \%$ biosensor

10 adherence.

11 Intervention: Feedback on big data from continuous glucose monitoring (CGM), its intersection

12 with other ecological datasets (exercise, mood, sleep), and other informational and motivational

13 elements (exercise videos, text-based exercise coach, self-monitoring diary).

14 Main Outcome Measures: Feasibility (use metrics, assessment completion), safety (mild and

15 severe hypoglycemia, diabetic ketoacidosis), acceptability (system usability scale, single items,

16 interview themes), standard clinical and psychosocial assessments.

17 Results: Participants increased exercise from a median of 0 (IQR 0, 41) to $64(20,129)$ minutes

18 per week $(\mathrm{p}=.004, \mathrm{~d}=0.71)$ with no severe hypoglycemia or ketoacidosis. Body mass index

19 increased $\left(29.5 \pm 5.1\right.$ to $\left.29.8 \pm 5.4 \mathrm{~kg} / \mathrm{m}^{2}, \mathrm{p}=.02, \mathrm{~d}=0.57\right)$. Highest satisfaction ratings were for

20 CGM use (89\%) and data on exercise and its intersection with CGM and sleep (94\%).

21 Satisfaction was primarily due to improved exercise management behavioral skills, although

22 derived motivation was transient. 
24 Conclusions: The use of personalized big data from biosensors to substantiate human-delivered, 25 client-centered exercise support for T1D is feasible and acceptable for interventions involving 26 big data collection. However, there is a need for more intensive, sustained support. The big data 27 could support informatics-based, automated motivational tools.

28

29 Keywords: Diabetes Mellitus, Type 1; Exercise; Behavior and Behavior Mechanisms; Mobile 30 phone

31 Clinical Relevance: A mobile application using personalized readings from wearable devices to 32 support beginner's exercise with type 1 diabetes was tested to solicit user feedback. 


\section{INTRODUCTION}

Type 1 Diabetes (T1D) affects 1.6 million Americans and is associated with micro and macro-vascular complications including cardiovascular disease. ${ }^{1}$ Standard treatment approaches to maintain blood glucose levels within a target range $(70-180 \mathrm{mg} / \mathrm{dL})$ include frequent glucose monitoring by fingersticks and continuous glucose monitoring (CGM), and adherence to complex dietary and insulin regimens. ${ }^{2}$ People with T1D must constantly adjust these factors to mitigate blood glucose fluctuations that occur with meals, exercise, and mental and physical stress. These fluctuations can lead to a profound fear of hypoglycemic episodes. ${ }^{3,4}$ T1D can also complicate weight management since efforts to maintain glycemic balance often result in overeating ${ }^{4}$ or overestimating insulin doses, which has anabolic effects associated with greater risk of obesity. ${ }^{5}$ Attention must also be paid to lipid and blood pressure measurements ${ }^{2}$ due to the high relative cardiovascular mortality risks ( $\sim 2$ to 12 -fold higher) for individuals with T1D. ${ }^{6}$

Research has prioritized interventions improving glycemic control (psychoeducation, ${ }^{7,8}$ diabetes devices, ${ }^{9}$ and digital platforms ${ }^{10}$ ) in T1D with minimal focus on overall cardiovascular risk (i.e., glycemic control plus other cardiovascular risk factors noted above). A recent systematic review concluded that exercise is linked to positive health outcomes in T1D that heavily impact cardiovascular risk (aerobic capacity, lipid profile, glycemic control). ${ }^{11}$ Unfortunately, most people with T1D do not practice regular exercise. ${ }^{12,13}$ Exercise is logistically challenging because it may cause hypo- or hyperglycemia depending on individual circumstances (magnitude and timing of most recent meal and insulin dose, any hypoglycemia in the past 24 hours, etc), which must be counteracted by intricate adjustments to insulin and diet. ${ }^{3,4,14}$

Continuous glucose monitoring (CGM), increasingly becoming standard of care for T1D can help support people to achieve safe glucose levels during exercise. ${ }^{2}$ By measuring glucose 
61 every few minutes CGM identifies trends and trajectories, not just "snapshot" values, helping the

62 user identify relationships among the timing of exercise (eg, morning vs afternoon, after vs before

63 mealtime insulin bolus), acute hypo- or hyper-glycemia, and overall time spent in the optimal

64 glucose range. ${ }^{15}$ The intersection of big CGM datasets with exercise can also improve confidence

65 and motivation for lifestyle change $\mathrm{e}^{16-18}$ but comprehensive interventions translating this

66 information into safe and sustainable exercise behavior for users with T1D are lacking.

67 Therefore, this study intervention uses big data from CGM intersected with other

68 ecological datasets (smartwatch exercise monitoring, mood and sleep diaries) and integrated with

69 motivational elements to promote behavioral skills, and uses feedback on health outcomes

70 resulting from these skills as additional information and motivation [i.e., information-motivation-

71 behavioral skills (IMBS) approach ${ }^{19}$ ]. The purpose of this study was to evaluate the feasibility,

72 safety, user satisfaction (i.e., acceptability), and estimate the probable magnitude of the pre-post

73 effect on exercise behavior and other exploratory outcomes (clinical, psychosocial) pertinent to

74 self-management of T1D.

75

76

77

78 Participants. Adults with T1D were recruited to participate between November 2019 and August

792020 by a combination of social media advertising, snowball sampling, in-person, and other

80 approaches fully described in a separate manuscript. ${ }^{20}$ The inclusion criteria were: $18-65$ years

81 old with $\geq 6$ mo diagnosis of T1D or other absolute insulin deficiency diabetes, inadequate

82 baseline exercise patterns ( $<3$ exercise sessions/wk), ${ }^{2,21}$ English literacy, current user of a

83 smartphone and CGM. Exclusion criteria were chronic disease or physical disability requiring

84 exercise adjustments outside the scope of the mobile intervention. 
85 Study Design. The study was a pre-post single-group design (Figure 1). Participants completed a

86 2-week baseline period that included clinical and psychosocial assessments plus observation

87 (CGM, insulin use, exercise, hip accelerometry) followed by a 10-week intervention with all

88 baseline measures repeated during the last two weeks. A physician (author S.W. or L.N.)

89 reviewed CGM and clinical events every 2 weeks.

90 Intervention Overview. We delivered the intervention through a customized mobile digital

91 application adapted from a commercial product (GlucoseZone ${ }^{\mathrm{TM}}$, Fitscript ${ }^{\mathrm{LLC}}$, New Haven, CT).

92 Its components (Table 1) were chosen to satisfy the information and motivation components of

93 the IMBS model and include feedback on health outcomes resulting from behavioral skills. ${ }^{19}$

\begin{tabular}{|c|c|c|}
\hline Component & Informational Aspects & Motivational Aspects \\
\hline $\begin{array}{l}\text { Exercise videos (on- } \\
\text { demand from } \\
\text { smartphone) led by } \\
\text { GlucoseZone instructor }\end{array}$ & $\begin{array}{l}\text { *Exercise techniques } \\
\text { *Exercise benefits for T1D }\end{array}$ & $\begin{array}{l}\text { *Visual display of expected health } \\
\text { impact } \dagger\end{array}$ \\
\hline $\begin{array}{l}\text { Text-based exercise } \\
\text { coach }\end{array}$ & *Exercise advice & *Personalization of messages \\
\hline $\begin{array}{l}\text { Self-monitoring of } \\
\text { exercise, barriers to } \\
\text { exercise, mood, and } \\
\text { sleep }\end{array}$ & $\begin{array}{l}\text { *Common barriers to } \\
\text { exerciset }\end{array}$ & *Self-monitoring \\
\hline $\begin{array}{l}\text { Monthly motivational } \\
\text { enhancement therapy } \\
\text { session including } \\
\text { biosensor feedback led } \\
\text { by principal } \\
\text { investigator }\end{array}$ & $\begin{array}{l}\text { *Reports of CGM and } \\
\text { exercise data } \\
* \text { Advice to change }\end{array}$ & $\begin{array}{l}\text { *Presentation of data to draw inferences } \\
\text { about CGM-exercise relationship } \\
\text { *Person-centered therapy }\end{array}$ \\
\hline \multicolumn{3}{|c|}{$\begin{array}{l}\dagger \text { †g, diagram of areas where muscle insulin sensitivity improves for a specific exercise. } \\
\text { †Choices included the profile of mood states (lacked positive feelings, had negative feelings, } \\
\text { lacked energy, fatigue), fear of hypoglycemia, app malfunction, lack of time/planning, or other. }\end{array}$} \\
\hline
\end{tabular}

95 Intervention Component \#1: Exercise videos. All exercise videos were taken from

96 GlucoseZone's publicly available commercial version (www.glucosezone.com), which has been

97 in circulation since 2018 with $\sim 13,700$ users globally. The video instructors hold a bachelor's- or

98 master's-level degree in an exercise-related field along with internal training and in-person 
99 experience coaching exercise for diabetes. Each video is 20-50 minutes long and includes

100 English guidance to complete an exercise routine interspersed with tips for diabetes management 101 around exercise and description of exercise benefits for diabetes that serve as motivation. The 102 routines are designed to be doable from a home setting. Participants could select routines 103 requiring no equipment, a $\$ 10$ set of resistance bands (Fit Simplify) loaned by the research team, 104 their own dumbbells or household items like frozen water bottles. The participants could choose 105 video series that progress in difficulty and duration or select single videos from a library filtered 106 by difficulty level, duration, type of exercise (aerobic or resistance), muscle groups, and mobility 107 limitations (knee-friendly, shoulder-friendly, chair-based). Flexibility and balance exercises were 108 also included. Most routines were interval-based in accordance with consensus recommendations 109 for glucose-stabilizing exercises, though participants could also select more continuous exercises 110 to achieve a glucose-lowering effect.

111 Intervention Component \#2: Text-based exercise coach. Participants could send text messages

112 through the app with exercise questions and receive a response from one of the certified exercise 113 instructors.

114 Intervention Component \#3: Self-monitoring of exercise and barriers. Participants received an 115 automated SMS each morning at self-reported expected waketime with a link to a secure 116 webform (Qualtrics, Provo, UT). A) Exercise completed without video guidance (eg, outdoor 117 activities, ballgames) was logged by type, start/stop time, and a Borg Rating of Perceived 118 Exertion. ${ }^{22}$ For video-guided exercise, this information was captured by the application usage log 119 and a post-survey of perceived exertion. B) If the participant had not exercised the previous day, 120 the form asked them to rank-order the prior day's barriers to exercise. Choices included moods 121 (lacked positive feelings, had negative feelings, lacked energy, fatigue), fear of hypoglycemia, 
122 app malfunction, lack of time/planning, or other. C) Hypothetical correlates of exercise behavior

123 were assessed including prior evening's fear of nocturnal hypoglycemia (5-point scale), ${ }^{4}$ prior

124 night's sleep quality (10-point numerical scale as per the Pittsburgh Sleep Diary), ${ }^{23}$ and fear of

125 hypoglycemia for the coming day (5-point scale). ${ }^{4}$ D) Safety information, including each episode

126 of hypoglycemia from the previous day [time of day, symptoms, and mild (self-treatable) versus

127 severe (needed external assistance to treat)]; and any adverse health events (hospitalization,

128 emergency room visit, diabetic ketoacidosis, acute illness, other), gathered every two weeks for

129 purposes of physician monitoring. E) Separate from the morning diaries, each video (component

130 \#1) queried the profile of mood states (positive feelings, negative feelings, energy, fatigue) by 1-

131 item subscales. ${ }^{24}$

132 Intervention Component \#4: Monthly motivational enhancement therapy session including

133 biosensor feedback. Participants wore their own CGM to capture $24 \mathrm{hr}$ blood glucose and the

134 Apple Watch 3 to capture exercise heart rate (mean absolute relative difference to

135 electrocardiography $\sim 3 \%) .{ }^{25}$ These devices were integrated with video usage logs and self-

136 monitoring data to produce a visual report and quantitative comparisons (Figure 2). The report

137 was reviewed by the principal investigator (G.A. trained by L.F., a clinical psychologist) with

138 participants in an open-ended discussion inviting responses from participants (e.g., "what do you

139 think about this information?’). Subsequent conversation focused on exercise levels, goals, and

140 barriers conducted in the nonconfrontational/empathic style of motivational enhancement

141 therapy which is intended to minimize participant resistance and emphasizes personal

142 responsibility for change. ${ }^{26}$

143 Assessments. Exercise was quantified from video usage logs and diaries, converted to metabolic

144 equivalent-minutes by Ainsworth intensities, ${ }^{27}$ and verified by Apple Watch heart rate readings 
145 [as a percentage of age-predicted maximum $(207-0.7 *$ age $)]$. The (relatively infrequent)

146 exercise performed during the 2-week baseline period was recalled day-by-day at the end of

147 baseline, a method we have demonstrated to be reliable $(r=0.79-0.97)$ and convergently valid

148 with weekly $\operatorname{logs}(\mathrm{r}=0.65-0.80) .{ }^{28}$ We also captured hip accelerometry over waking hours

149 during 7 days of baseline and final intervention week (Figure 1) (Actigraph GT9X, Pensicola,

150 FL), classifying $\geq 2020$ counts/min as moderate-to-vigorous physical activity, ${ }^{29}$ although the

151 videos dictated many static exercises (e.g., core exercise) that would not be accelerometer-

152 registered. Methods for our clinical assessments (Table 2) are detailed in our earlier

153 manuscript. ${ }^{20}$

154 Satisfaction Survey included the system usability scale ${ }^{30}$ for each technical component (10

155 Likert-style items assessing aspects such as ease of use and degree of technical support needed)

156 and a single Likert-style item for each biosensor feedback component of the monthly

157 discussions. Participants also completed a semi-structured interview with the principal

158 investigator asking what initially made them interested in the study and what they did and did not

159 like about specific components. These were audio recorded, de-identified, and transcribed for

160 analysis.

161 Analysis. Feasibility metrics were usage of each component and assessment completion. Safety

162 metrics were self-reported occurrence of mild hypoglycemia, severe hypoglycemia, and diabetic

163 ketoacidosis. Acceptability metrics were percentage above normative system usability scale

164 average for technology products (70 / 100) and percentage satisfied or very satisfied for

165 discussion components (i.e., 4 or 5 out of 5). 
Outcomes were compared between the baseline and follow-up by intention-to-treat, using

167 Cohen's d and paired t-tests after verifying normality and log-transforming where needed.

168 Analyses were performed in SPSS 24.0 for Windows (Armonk, NY).

169 Interviews were analyzed using qualitative description ${ }^{31}$ using Atlas.ti $^{\mathrm{TM}} 7$ software

170 (Berlin, Germany) by a single coder (M.D.). The coder read all transcripts, established initial

171 codes inductively from a subset, then coded all others and grouped codes and quotes into themes.

172

\section{ETHICAL CONSIDERATIONS}

The study was approved by the Yale University Institutional Review Board, in accordance with

176 the Declaration of Helsinki. All participants completed an approved copy of the informed

177 consent document prior to study procedures. Study compensation was US \$100.38 prorated by

178 mobile diary completion (average \$91.75).

\section{RESULTS}

Participants $(11 \mathrm{~F}, 9 \mathrm{M})$ were $42.3 \pm 15.0$ years old with $20.5 \pm 15.3$ years of diabetes. Most had

183 T1D (90\%) and 10\% had Latent Autoimmune Diabetes of Adulthood. Some demographic

184 advantages appeared overrepresented compared to the general T1D population ${ }^{9}$ including

185 education (70\% bachelor's or higher), household income ( $85 \% \geq \$ 50 \mathrm{k}$ per year, $50 \% \geq \$ 80 \mathrm{k}$ per

186 year), Non-Hispanic white race/ethnicity (95\%, with 5\% Hispanic white), and usage of a

187 continuous subcutaneous insulin infusion pump (85\%). The remaining $15 \%$ (i.e., 3 participants)

188 used multiple daily injections, among whom 2 complied with the Bluetooth InPen (Companion

189 Medical) during the study and the $3^{\text {rd }}$ preferred to log manually using the InPen's mobile

190 application. Their CGMs included the Dexcom G6 (40\%), G5 (10\%), G4 (5\%), Medtronic 670G

191 (35\%), and Abbott Freestyle Libre (10\%). On average they had indications of cardiovascular risk 
192 including inadequate physical activity, overweight to obese body mass index, prehypertension, 193 and above-target A1c (Table 2). CGM profile also indicated sub-optimal control ( $>25 \%$ above

194 target range, $<70 \%$ in range). ${ }^{2}$ They rated their sleep quality above average.

195 Feasibility. Participants exercised a median of 31 (IQR 12, 58) minutes per week with the videos 196 and $28(6,69)$ minutes per week without video guidance. Participants rarely texted the coaches 197 (average $<1 \mathrm{x} /$ month) but $85 \%$ of them attended both monthly calls. Completion of assessments, 198 diaries, and accelerometer wear were $\geq 85 \%$ (Table 2).

199 Safety. There was no ketoacidosis or severe hypoglycemia. Mild hypoglycemia was self-reported 200 a median of 1.5 (IQR 1.1, 4.0) times per week.

201 Efficacy outcomes. Participants significantly increased their exercise and body mass index

202 (Table 2). They tended to slightly decrease blood pressure, A1c, mean sensor glucose and to 203 slightly increase waist circumference and quality of sleep. Total daily insulin dose was not 204 different.

205

206

207

208

209

210

211

212

213

214 


\begin{tabular}{|c|c|c|c|c|c|}
\hline Metric & Baseline & Last 2 weeks & $P \dagger$ & Cohen's d & Data completion \\
\hline \multicolumn{6}{|l|}{ EXERCISE } \\
\hline $\begin{array}{l}\text { Logged exercise duration } \\
(\mathrm{min} / \mathrm{wk})^{* \dagger}\end{array}$ & $0(0,21)$ & $64(20,129)$ & .004 & 0.71 & \multirow[t]{2}{*}{$100 \%$ logs captured } \\
\hline $\begin{array}{l}\text { Logged exercise volume } \\
(\mathrm{MET}-\mathrm{min} / \mathrm{wk})\end{array}$ & $0(0,156)$ & $256(91,614)$ & .001 & 0.91 & \\
\hline $\begin{array}{l}\text { Accelerometer-measured } \\
\text { moderate-to-vigorous physical } \\
\text { activity in bouts } \geq 10 \mathrm{~min} \\
(\mathrm{~min} / \mathrm{wk}) \dagger\end{array}$ & $0(0,89)$ & $18(0,88)$ & .27 & 0.25 & $\begin{array}{l}90 \% \text { returned, } \\
\text { worn } 6.8 \pm 0.5 \text { out of } \\
7 \text { days for } 14.7 \pm 1.5 \\
\text { waking hours per } \\
\text { day }\end{array}$ \\
\hline \multicolumn{6}{|l|}{ CLINICAL } \\
\hline Body mass index $\left(\mathrm{kg} / \mathrm{m}^{2}\right)$ & $29.5 \pm 5.1$ & $29.8 \pm 5.4$ & .02 & 0.57 & \multirow{5}{*}{$85 \%$ completed } \\
\hline Waist circumference $(\mathrm{cm})$ & $92.1 \pm 14.7$ & $94.0 \pm 15.6$ & .10 & 0.39 & \\
\hline 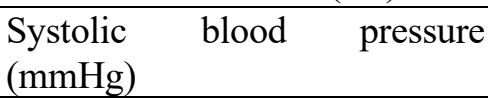 & $123 \pm 16$ & $119 \pm 16$ & .06 & -0.45 & \\
\hline $\begin{array}{l}\text { Diastolic blood pressure } \\
(\mathrm{mmHg})\end{array}$ & $77 \pm 9$ & $76 \pm 6$ & .35 & -0.21 & \\
\hline HbA1c $(\%)$ & $7.2 \pm 1.1$ & $7.0 \pm 0.9$ & .07 & -0.42 & \\
\hline $\begin{array}{l}\text { Mean continuous glucose } \\
(\mathrm{mg} / \mathrm{dL})\end{array}$ & $159 \pm 40$ & $154 \pm 39$ & .09 & -0.41 & \multirow{5}{*}{$\begin{array}{l}95 \% \text { returned, worn } \\
90.4 \pm 8.8 \% \text { of time }\end{array}$} \\
\hline Glucose time $<70 \mathrm{mg} / \mathrm{dL}(\%)$ & $2.3 \pm 2.7$ & $2.7 \pm 3.6$ & .52 & 0.15 & \\
\hline $\begin{array}{l}\text { Glucose time } 70-180 \mathrm{mg} / \mathrm{dL} \\
(\%)\end{array}$ & $68.9 \pm 22.4$ & $70.2 \pm 23.4$ & .72 & 0.08 & \\
\hline Glucose time $>180 \mathrm{mg} / \mathrm{dL}$ & $28.7 \pm 23.6$ & $27.1 \pm 24.8$ & .65 & -0.11 & \\
\hline $\begin{array}{l}\text { Glucose variability (coefficient } \\
\text { of variation, } \% \text { ) }\end{array}$ & $30.9 \pm 6.3$ & $29.5 \pm 6.3$ & .18 & -0.32 & \\
\hline Insulin use $(\mathrm{U} / \mathrm{kg})$ & $0.64 \pm 0.23$ & $0.65 \pm 0.28$ & .71 & 0.09 & $90 \%$ logs captured \\
\hline Sleep quality diary $(0-10)$ & $6.8 \pm 1.4$ & $7.2 \pm 1.5$ & .10 & 0.41 & $\begin{array}{l}91.4 \pm 14.1 \% \\
\text { completed }\end{array}$ \\
\hline \multicolumn{6}{|c|}{$\begin{array}{l}\text { *Verified by exercise video usage and exercise heart rate on Apple Watch } 3(\mathbf{6 2 . 2} \pm \mathbf{9 . 5 \%} \text { age- } \\
\text { predicted maximum }) \text { including static exercises not registered by accelerometer. } \\
\dagger \text { Negatively skewed, so log-transformed for analysis and reported as median }\left(25^{\text {th }} \% \text { 'ile, } 75^{\text {th }} \% \text { 'ile }\right) \text {. } \\
\text { Others were normally distributed and reported as mean } \pm \text { SD. }\end{array}$} \\
\hline
\end{tabular}

216 Acceptability surveys. Among the 18 / 20 participants who completed the survey, 67\% said they

217 were satisfied or very satisfied with the intervention and $83 \%$ said they would recommend the

218 program to a friend or family member with T1D. Virtually all survey respondents reported

219 above-average satisfaction with their CGM devices (Table 3). Otherwise, the most satisfying

220 components were discussion of specific subsets of the biosensor/diary data at the monthly calls,

221 mostly those involving exercise or its intersection with another biosensor/diary variable. Other 
222 technical devices besides the CGM were rated less highly. Discussion of diary variables were

223 rated lower (unless combined with biosensor data as mentioned above) and daily usage of the

224 diaries was unsatisfying. Texting with the coach was unsatisfying on the rare occasions it was

225 utilized.

226

\begin{tabular}{|c|c|c|c|}
\hline Component & $\begin{array}{l}\text { Proportion reporting } \\
\text { above-average* } \\
\text { satisfaction }\end{array}$ & $\begin{array}{l}\text { Mean Score } \\
\text { (SD) out of } 100\end{array}$ & $\mathbf{N \dagger}$ \\
\hline Discussions of exercise and blood glucose & $94 \%$ & $88(16)$ & 17 \\
\hline Discussions of exercise & $94 \%$ & $87(16)$ & 17 \\
\hline Discussions of exercise and sleep & $94 \%$ & $81(24)$ & 17 \\
\hline Continuous glucose monitor & $89 \%$ & $85(13)$ & 18 \\
\hline Discussions of glucose & $82 \%$ & $79(18)$ & 17 \\
\hline Discussions of exercise and mood & $82 \%$ & $75(25)$ & 17 \\
\hline Apple Watch & $78 \%$ & $72(21)$ & 18 \\
\hline Videos & $72 \%$ & $69(18)$ & 18 \\
\hline Insulin Device & $67 \%$ & $77(17)$ & 18 \\
\hline Discussions of mood & $65 \%$ & $68(23)$ & 17 \\
\hline Discussions of sleep & $59 \%$ & $68(25)$ & 17 \\
\hline Discussions of exercise barriers & $53 \%$ & $65(27)$ & 17 \\
\hline Texting with coach & $33 \%$ & $57(19)$ & 18 \\
\hline Diaries & $0 \%$ & $26(11)$ & 18 \\
\hline \multicolumn{4}{|c|}{$\begin{array}{l}\text { Bolded indicates discussion topic assessed by single item. Others assessed by system usability scale. } \\
\dagger \text { Participants skipped items they did not use, and } 2 \text { participants declined to complete the survey. } \\
\text { *Defined as } \geq 70 \text { out of } 100 \text { (above worldwide average for a technology product, "satisfied" or "very } \\
\text { satisfied" for a discussion component) }\end{array}$} \\
\hline
\end{tabular}

227

228

229

230

231

232

233

234

235

236

Acceptability Interviews

Theme 1: Exercise management behavioral skills. Participants said they learned skills including reducing pre-exercise insulin doses, using exercise to account for overconsumption of carbohydrates, tailoring the timing and type of exercise to optimize glycemic control, and adjusting insulin-to-carbohydrate ratio for exercise-induced insulin sensitivity changes. Many participants stated these skills would help them exercise even more in the future even though time/planning limited how much they achieved during the intervention. A participant who exercised just 1x per month (female, 20 years old) said, "I did notice after doing exercise 
237 sessions the glucose went down, so the exercise does work." Another participant who exercised

238 1-2x per week (male, 50 years old) said, "this program is helping me feel more comfortable in

239 the exercise space, more comfortable doing the programs and more comfortable exercising, and I

240 can see and feel results by doing it, if I can just get into the habit of doing it more."

242 Theme 2: Motivation. Although some participants enrolled because of desiring to learn more

243 skills (c.f. theme 1), the most common reason for enrollment was wanting more accountability

244 and "background motivation" to exercise. Some reported having adequate exercise on some days

245 or even some weeks of the year but not others, and they enrolled in the intervention to achieve

246 greater consistency. By the end of the intervention, some reported this need for motivation was

247 met by the monthly motivational enhancement therapy sessions with the principal investigator,

248 more so reviewing the big data (Figure 2) than interacting with the principal investigator. Many

249 others, however, reported the motivation was transient and could be sustained with more

250 frequent feedback and inferences from specific subsets of the big data (e.g., drawing causality

251 between specific exercises and improvements to insulin sensitivity and glycemic control).

252

253

254

255

256

257

\section{DISCUSSION}

\section{Principal Findings}

The purpose of this study was to pilot an intervention leveraging big data from biosensors

258 safe and feasible, a substantial majority of participants found it satisfying and recommendable, and

259 data indicate potential to moderately increase exercise levels if it were tested in a larger trial with

260 a randomized controlled design. Nonetheless, this moderate increase (from a median of 4 to 64

261 minutes per week) would clearly fall beneath recommended levels of 150 minutes per week ${ }^{2}$. 
262 These findings indicate that the current intervention holds some promise but needs refining before

263 conducting a larger trial.

264 Guidance for such refinement was obtained from the participants through a satisfaction 265 survey and interview. The most appealing component was discussion of data about exercise and

266 its intersection with health outcomes, including big data from CGM and ecological momentary

267 assessment of sleep and mood variables. They rated these big data discussions higher than many

268 popular commercial products they were using (insulin device, Apple Watch, exercise videos

269 tailored to T1D) and similarly to general CGM use, which has recently revolutionized diabetes

270 care. ${ }^{2,15-18}$

271 When asked why they liked the big data discussions, participants stated that they improved

272 their exercise management behavioral skills related to T1D. Nonetheless, some failed to increase

273 regular exercise due to lack of motivation. Many noted that the big data discussions improved their

274 motivation only transiently and they would like to see more sophisticated inferences. For example,

275 recommended insulin-to-carbohydrate ratios could be fluidly calculated from exercise-CGM

276 relationships rather than a static number set at quarterly clinician visits.

277 Implications for Future Interventions

278 These findings suggest that the collection and use of big data was feasible and appealing,

279 but more frequent motivational tools should be developed and enlisted. One such possibility is a

280 just-in-time adaptive intervention, in which big data are used to machine-learn predictors of a

281 vulnerable state and tailor encouragement accordingly. ${ }^{32}$ For example, if high blood glucose

282 variability is a vulnerable state predictor, the just-in-time message meeting its occurrence would

283 read: "Sometimes blood glucose can go up and down. You can still be active using the strategies

284 you and your provider have discussed." A second possibility is personalized assessment of 
285 exercise's causal impact upon CGM after adjustment for covariates measured as frequently as the

286 CGM including insulin-on-board, Apple Watch steps at sub-exercise intensity, and carbohydrates

287 self-reported into insulin delivery device (mathematical examples and graphics separately

288 published ${ }^{33}$ ). This could provide automated personalized feedback to encourage exercise that is

289 improving glucose levels or modifying exercise that is not (e.g., switch from resistance to aerobic).

290 In addition, it provides a digital phenotype ${ }^{34}$ that could be aligned with other big data sources (e.g.

291 genomics) that may explain and predict the health response to exercise.

292 Comparison to Previous Work

293 Aligned with other exercise programs for T1D, the direction of effect sizes indicated

294 potential for benefit to glycemic control and blood pressure but not body weight or adiposity. ${ }^{11}$

295 Management of exercise often requires carbohydrate correction of blood glucose, complicating

296 weight management. ${ }^{35}$

297 Limitations

298 While this study was designed to identify insights that can guide refinement of the 299 intervention, limitations due to sample size and design precluded testing efficacy and maintenance.

300 Additionally, the sample was biased toward individuals with demographic advantage and users of 301 CGM technology. CGM use has quadrupled over the past decade due to its heavy clinical 302 endorsement, but its adoption has lagged behind in non-white populations. ${ }^{36}$ Finally, only one 303 motivation enhancement therapist was utilized, who also happened to be the principal investigator; 304 which may have limited the generalizability of our findings and generated some bias by 305 participants to give favorable reviews.

306 Conclusions

307 This study personalized big data from biosensors to substantiate human-delivered, client- 
308 centered exercise support for T1D. Despite limitations, the moderate beneficial effect on exercise

309 behavior and small-to-moderate beneficial effects on glycemic control and blood pressure support

310 potential for efficacy if the strategies to intensify the intervention taken from the acceptability

311 interviews can be incorporated.

312

\section{REFERENCES}

314 1. Centers for Disease Control and Prevention. National diabetes statistics report.

315 https://www.cdc.gov/diabetes/data/statistics-report/index.html. Updated 2020. Accessed

316 February 27, 2021.

317 2. American Diabetes Association. 2. classification and diagnosis of diabetes: Standards of

318 medical care in diabetes-2020. Diabetes Care. 2020;43(Suppl 1):S14-S31.

319 3. Brazeau AS, Rabasa-Lhoret R, Strychar I, Mircescu H. Barriers to physical activity among 320 patients with type 1 diabetes. Diabetes Care. 2008;31(11):2108-2109.

321 4. Martyn-Nemeth P, Quinn L, Penckofer S, Park C, Hofer V, Burke L. Fear of hypoglycemia:

322 Influence on glycemic variability and self-management behavior in young adults with type 1

323 diabetes. J Diabetes Complications. 2017;31(4):735-741.

324 5. Nathan DM, DCCT/EDIC Research Group. The diabetes control and complications

325 trial/epidemiology of diabetes interventions and complications study at 30 years: Overview.

326 Diabetes Care. 2014;37(1):9-16. 
327 6. Orchard TJ, Forrest KY, Kuller LH, Becker DJ, Pittsburgh Epidemiology of Diabetes

328 Complications Study. Lipid and blood pressure treatment goals for type 1 diabetes: 10-year

329 incidence data from the pittsburgh epidemiology of diabetes complications study. Diabetes Care.

$330 \quad 2001 ; 24(6): 1053-1059$.

331 7. Amsberg S, Anderbro T, Wredling R, et al. A cognitive behavior therapy-based intervention

332 among poorly controlled adult type 1 diabetes patients--a randomized controlled trial. Patient

333 Educ Couns. 2009;77(1):72-80.

334 8. Pyatak EA, Carandang K, Vigen CLP, et al. Occupational therapy intervention improves

335 glycemic control and quality of life among young adults with diabetes: The resilient,

336 empowered, active living with diabetes (REAL diabetes) randomized controlled trial. Diabetes

337 Care. 2018;41(4):696-704.

338 9. Foster NC, Beck RW, Miller KM, et al. State of type 1 diabetes management and outcomes 339 from the T1D exchange in 2016-2018. Diabetes Technol Ther. 2019;21(2):66-72.

340 10. Bonoto BC, de Araujo VE, Godoi IP, et al. Efficacy of mobile apps to support the care of

341 patients with diabetes mellitus: A systematic review and meta-analysis of randomized controlled

342 trials. JMIR Mhealth Uhealth. 2017;5(3):e4.

343 11. Wu N, Bredin SSD, Guan Y, et al. Cardiovascular health benefits of exercise training in

344 persons living with type 1 diabetes: A systematic review and meta-analysis. $J$ Clin Med.

$3452019 ; 8(2): 10.3390 / j \mathrm{~cm} 8020253$. 
346 12. McCarthy MM, Funk M, Grey M. Cardiovascular health in adults with type 1 diabetes. Prev

347 Med. 2016;91:138-143.

348 13. Bohn B, Herbst A, Pfeifer M, et al. Impact of physical activity on glycemic control and

349 prevalence of cardiovascular risk factors in adults with type 1 diabetes: A cross-sectional

350 multicenter study of 18,028 patients. Diabetes Care. 2015;38(8):1536-1543.

351 14. Kennedy A, Narendran P, Andrews RC, Daley A, Greenfield SM, EXTOD Group. Attitudes

352 and barriers to exercise in adults with a recent diagnosis of type 1 diabetes: A qualitative study of

353 participants in the exercise for type 1 diabetes (EXTOD) study. BMJ Open. 2018;8(1):e017813-

$354 \quad 2017-017813$.

355 15. Houlder SK, Yardley JE. Continuous glucose monitoring and exercise in type 1 diabetes:

356 Past, present and future. Biosensors (Basel). 2018;8(3):10.3390/bios8030073.

357 16. Dyck RA, Kleinman NJ, Funk DR, Yeung RO, Senior P, Yardley JE. We can work (it) out

358 together: Type 1 diabetes boot camp for adult patients and providers improves exercise self-

359 efficacy. Can J Diabetes. 2018;42(6):619-625.

360 17. Pickup JC, Ford Holloway M, Samsi K. Real-time continuous glucose monitoring in type 1

361 diabetes: A qualitative framework analysis of patient narratives. Diabetes Care. 2015;38(4):544-

362550.

363 18. Ehrhardt N, Al Zaghal E. Behavior modification in prediabetes and diabetes: Potential use of 364 real-time continuous glucose monitoring. J Diabetes Sci Technol. 2019;13(2):271-275. 
365 19. Fisher WA, Kohut T, Schachner H, Stenger P. Understanding self-monitoring of blood

366 glucose among individuals with type 1 and type 2 diabetes: An information-motivation-

367 behavioral skills analysis. Diabetes Educ. 2011;37(1):85-94.

368 20. Ash GI, Griggs S, Nally LM, et al. Evaluation of web-based and in-person methods to recruit 369 adults with type 1 diabetes for a technology-based exercise intervention: Prospective

370 observational study JMIR Preprints. 2021;28309. Available on-line:

371 https://preprints.jmir.org/preprint/28309

372 21. Tonstad S, Herring P, Lee J, Johnson JD. Two physical activity measures: Paffenbarger

373 physical activity questionnaire versus aerobics center longitudinal study as predictors of adult-

374 onset type 2 diabetes in a follow-up study. Am J Health Promot. 2018;32(4):1070-1077.

375 22. Haddad M, Stylianides G, Djaoui L, Dellal A, Chamari K. Session-RPE method for training 376 load monitoring: Validity, ecological usefulness, and influencing factors. Front Neurosci. $377 \quad 2017 ; 11: 612$.

378 23. Monk TH, Reynolds CF,3rd, Kupfer DJ, et al. The pittsburgh sleep diary. J Sleep Res. 379 1994;3:111-120.

380 24. Curran SL, Andrykowski MA, Studts JL. Short form of the profile of mood states (POMS381 SF): Psychometric information. Psychol Assess. 1995;7:80-83.

382 25. Fuller D, Colwell E, Low J, et al. Reliability and validity of commercially available wearable 383 devices for measuring steps, energy expenditure, and heart rate: Systematic review. JMIR $384 \quad$ Mhealth Uhealth. 2020;8(9):e18694. 
386 therapy manual: A clinical research guide for therapists treating individuals with alcohol abuse

387 and dependence. Rockville, MD: U.S. Department of Health and Human Services; 1999.

388 27. Ainsworth BE, Haskell WL, Herrmann SD, et al. 2011 compendium of physical activities: A 389 second update of codes and MET values. Med Sci Sports Exerc. 2011;43(8):1575-1581.

390 28. Panza GA, Weinstock J, Ash GI, Pescatello LS. Psychometric evaluation of the timeline 391 followback for exercise among college students. Psychol Sport Exerc. 2012;13(6):779-788.

392 29. Troiano RP, Berrigan D, Dodd KW, Masse LC, Tilert T, McDowell M. Physical activity in 393 the united states measured by accelerometer. Med Sci Sports Exerc. 2008;40(1):181-188.

394 30. Bangor A, Kortum P. Determining what individual SUS scores mean: Adding an adjective 395 rating scale. Journal of Usability Studies. 2009;4 (3):114-123.

396 31. Sandelowski M. What's in a name? qualitative description revisited. Res Nurs Health. $397 \quad 2010 ; 33(1): 77-84$.

399 mobile health: Key components and design principles for ongoing health behavior support. Ann 400 Behav Med. 2018;52(6):446-462.

401 33. Liu J, Spakowicz DJ, Ash GI, et al. Bayesian structural time series for biomedical sensor 402 data: A flexible modeling framework for evaluating interventions. bioRxiv.

403 2020:2020.03.02.973677. doi: 10.1101/2020.03.02.973677. Available on-line:

404 https://www.biorxiv.org/content/10.1101/2020.03.02.973677v2 
405 34. Fagherazzi G. Deep digital phenotyping and digital twins for precision health: Time to dig 406 deeper. J Med Internet Res. 2020;22(3):e16770.

407 35. Driscoll KA, Corbin KD, Maahs DM, et al. Biopsychosocial aspects of weight management 408 in type 1 diabetes: A review and next steps. Curr Diab Rep. 2017;17(8):58-017-0892-1.

409 36. Agarwal S, Schechter C, Gonzalez J, Long JA. Racial-ethnic disparities in diabetes 410 technology use among young adults with type 1 diabetes. Diabetes Technol Ther. 2020. 
CGM, automated insulin delivery logging,

Apple Watch, monthly recall of daily exercise behaviors

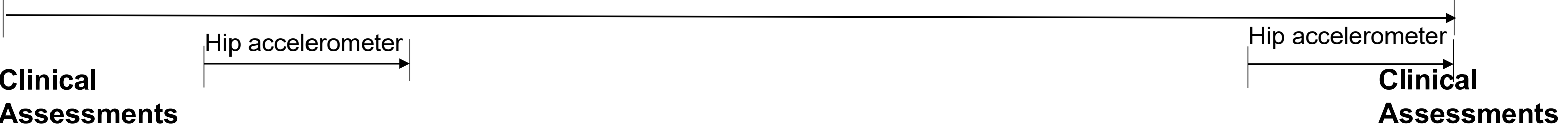

Week-2

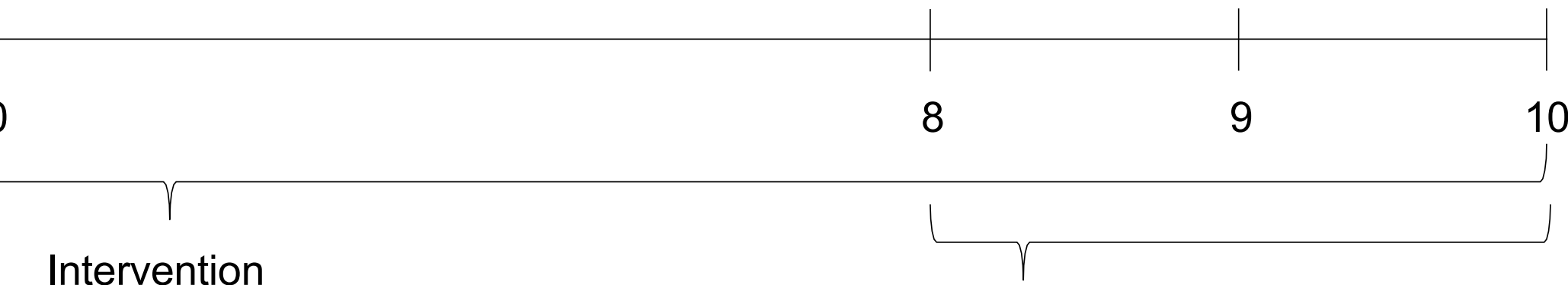

Baseline

*On Demand exercise videos

*Text-based exercise coach

Follow-up window

*Self-monitoring daily diaries of

exercise, sleep, mood states

*Monthly motivational enhancement

therapy session including feedback

from CGM, Apple Watch, and self-

monitoring

Figure 1. Study design 


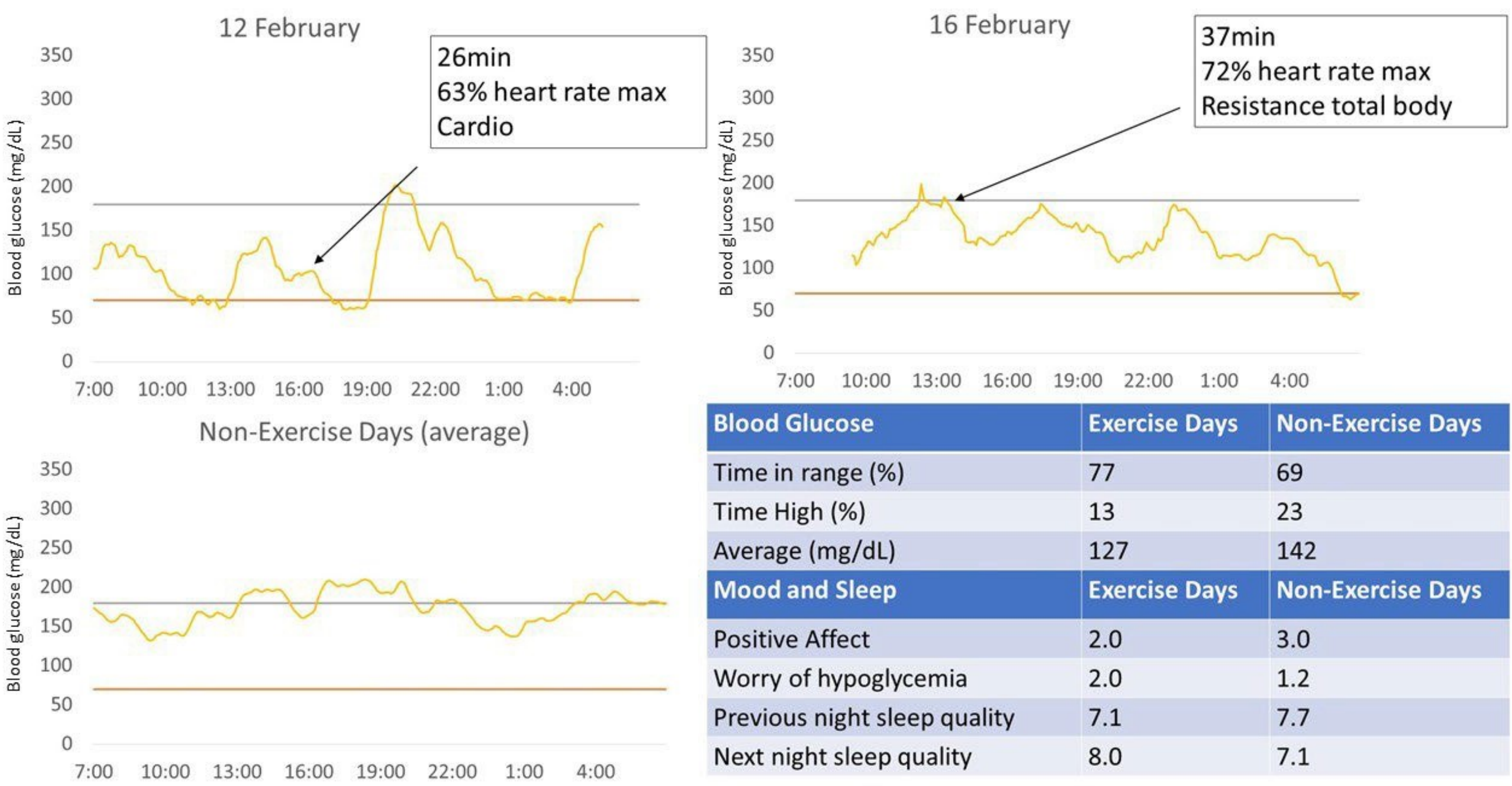

Figure 2. Example of personalized big data at monthly motivational enhancement therapy sessions. Blood glucose data also contained \% time low $(<70 \mathrm{mg} / \mathrm{dL})$ and variability (coefficient of variation). Prior to depicting this intersection of variables, the report contained exercise (total minutes, total days, average intensity by heart rate / perceived exertion / workout video difficulty) and continuous blood glucose summary statistics in isolation, compared to clinical targets ( 150 minutes exercise per week, blood glucose mean $<156 \mathrm{mg} / \mathrm{dL}$, time in range $>70 \%$, time above range $<25 \%$, time below range $<4 \%$ ). The report ended with tables of mood states before/after exercise and diary-reported exercise barriers ranked by frequency. 